\title{
Er:YAG laser assisted vestibuloplasty: A case report
}

\author{
Gordana Kovacevska ${ }^{1,}$ " , Georgi Tomov ${ }^{2}$, Petar Baychev ${ }^{3}$, Aleksandar Kovacevski ${ }^{4}$, \\ Vesna Andreevska ${ }^{5}$ \\ ${ }^{1}$ Faculty of Dentistry, University „Ss. Kiril i Metodij”, Clinic for prosthodontics, PHO Dental clinical center “Sv. Pantelejmon”, Skopje, \\ R. Macedonia \\ ${ }^{2}$ Department of Oral Pathology, Faculty of Dental Medicine, Medical University, Plovdiv, Bulgaria \\ ${ }^{3}$ Private dental clinic, Sofia, Bulgaria \\ ${ }^{4}$ Private dental clinic, Impacta Dental, Skopje, R. Macedonia \\ ${ }^{5}$ Clinic for orthodontics, PHO Dental clinical center “Sv. Pantelejmon”, Skopje, R. Macedonia
}

Email address:

g_kovacevska@hotmail.com (G. Kovacevska)

\section{To cite this article:}

Gordana Kovacevska, Georgi Tomov, Petar Baychev, Aleksandar Kovacevski, Vesna Andreevska. Er:YAG Laser Assisted Vestibuloplasty: A Case Report. Journal of Surgery. Vol. 1, No. 4, 2013, pp. 59-62. doi: 10.11648/j.js.20130104.13

\begin{abstract}
The principle of a suction cup is used to retain an upper full denture. Alveolar resorption results in loss of the vestibular depth and in diminished functional surface to overcome lateral forces. Traditional surgery has the following characteristics in common-need for incisions with steel scalpels, mechanical excision of the muscle attachment from the periosteum, placement of sutures, significant postoperative discomfort, and delayed healing. When the benefits and risks of alternative treatment modalities are taken into account for this mechanical surgical procedure, minimally invasive laserassisted soft-tissue excision and ablation seems to be very attractive technique. In the presented case report we used an Er:YAG laser (LiteTouch, Syneron, Israel) to deep the oral vestibulum of upper jaw in edentulous patient. Therefore, were indicated, we recommend the laser assisted operation technique for the partial vestibuloplasty to assure the patients a better postoperative outcome.
\end{abstract}

Keywords: Edentulous Patient, Er:YAG Laser, Vestibuloplasty

\section{Introduction}

Premature loss of the natural teeth results in an early and continuing retraction of the alveolar bone. Functional loading with dentures can slow down this atrophy, whereas poorly fitting dentures will accelerate this bone resorption. The principle of a suction cup is used to retain an upper full denture. The suction valve is located in the mucosa whereas the alveolar process withstands lateral and vertical forces during mastication and also during parafunction. Alveolar resorption results in loss of the vestibular depth and in diminished functional surface to overcome lateral forces. Mucosal ligaments on the other hand become more important and can break the suction seal. Early in the last century Kazanijan and Pilchler [1] tried to reconstruct the vestibular height using a palatally pedicled flap. In the early 50ties of IXX century vestibuloplasties with free epithelialization, dermal grafts and later with free gingival graft were inaugurated to create the necessary vestibular height needed for a denture [1].

Traditional surgery has the following characteristics in common-need for incisions with steel scalpels, mechanical excision of the muscle attachment from the periosteum, placement of sutures, significant postoperative discomfort and delayed healing. When the benefits and risks of alternative treatment modalities are taken into account for this mechanical surgical procedure, minimally invasive laser-assisted soft-tissue excision and ablation seems to be very attractive technique. Akin $\mathrm{H}$, et all [2] evaluating the effect of various surface treatments on the shear bond strength of the two chemically different denture base resins-polymethyl methacrylate (PMMA) and urethane dimethacrylate (UDMA), concluded that laser-irradiation of the adhesive surface was found to be ineffective on improving bond strength of acrylic denture teeth to denture base resin.

\section{Oral Soft Tissue Laser Procedures}

Previously, the continuous wave diode or pulsed $\mathrm{CO}_{2}$ laser have been used as a surgical tools for precise cutting and coagulating of oral soft tissues $[3,4,5,6]$. Surgeons 
using older continuous wave or pulsed $\mathrm{CO}_{2}$ lasers for softtissue excisional procedures have previously needed to work very quickly to minimize unwanted thermal damage to the surrounding tissues and bone $[3,5]$. If the soft-tissue procedure is performed with Er:YAG, the potential for thermal damage is greatly minimized, and the window of available working time is greatly expanded [7]. This can be accomplished because of the unique characteristics and photobiology of the Er:YAG laser tissue interaction. In contrast to other laser systems the Er:YAG does not have haemostatic properties, but the healing process after Er:YAG laser surgery is faster, without thermal damages and necrosis [8]. With the addition of the Er:YAG laser, the general dentist is presented with a less stressful and more beneficial treatment protocol for soft-tissue excisional procedures than previously available with the older continuous wave diode or pulsed $\mathrm{CO}_{2}$ lasers alone [9].

Relative reconstruction of the oral vestibulum height is a surgical procedure that is usually painful for the patient and is prone to relapse. Main aim of this case report was to evaluate the effects of a Er:YAG laser assisted operation technique on the postoperative outcome of edentulous patient, undergoing partial vestibuloplasty.

\section{Case Report}

76-year-old female patient was referred to laser dentistry office in the Faculty of Dental Medicine, Plovdiv, Bulgaria for vestibuloplasty prior to renewal of her full denture in the maxillary arch. The patient had a six months lasting history with full upper denture, but functional problems were reported. Mucosal ligaments were found during clinical examination. Vestibular depth measurements were done prior and after surgery using paranasal and distal sites tests (Fig. 1). The patient was operated using laser assisted technique for vestibuloplasty. After local anesthesia, using $4 \%$ articaine with epinephrine $1 / 200000$ (Ubistesin $\AA$ ), an incision was performed at the muco-gingival junction using 1300-micron sapphire tip, contact mode, power $200 \mathrm{~mJ}, 35$ $\mathrm{Hz}$ (Fig.2). The laser apparatus used was an Er:YAG laser (LiteTouch, Syneron Medical, Israel.).

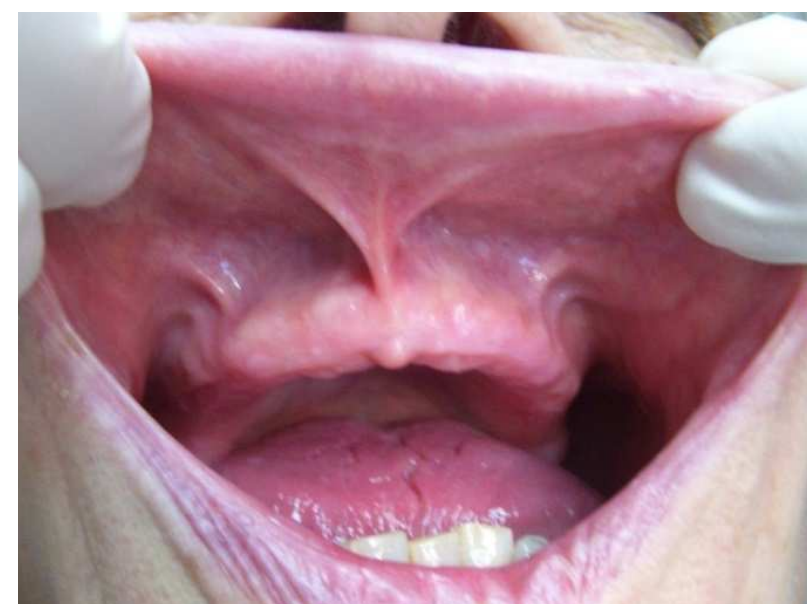

Figure 1. The paranasal test revealed mucosal ligaments.

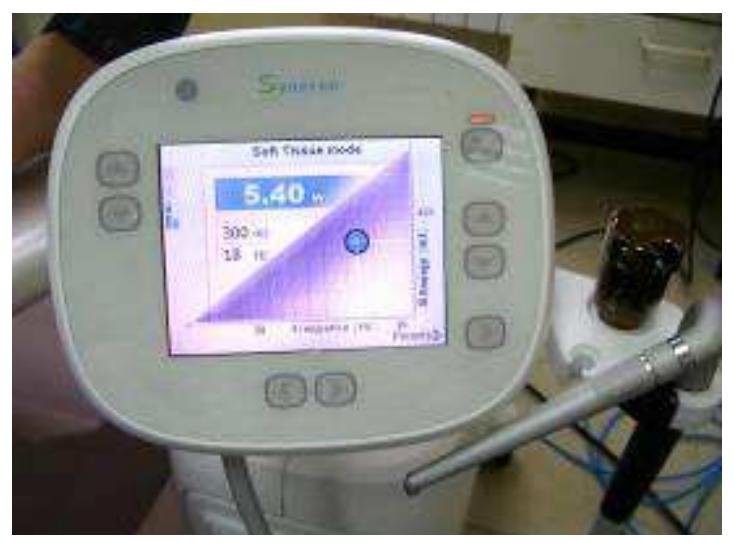

Figure 2. Laser parameters used for vestibuloplasty.

After supraperiostal preparation, the mobilized soft tissue was fixed high in the fornix without sutures (Fig. 3, 4), using the preexisting upper denture relined with a periodontal pack (Coe-Pak $\left.{ }^{\circledR}\right)$ and extended into the newly formed vestibule (Fig. 5, 6). The patient was instructed to wear the denture constantly and only remove it for cleaning. The patient was follow up after 1 day, 1, 3, 6 weeks and 6 months. The vestibular height in the paranasal and distal region, was taken at 1 week and 6 months follow up examination.

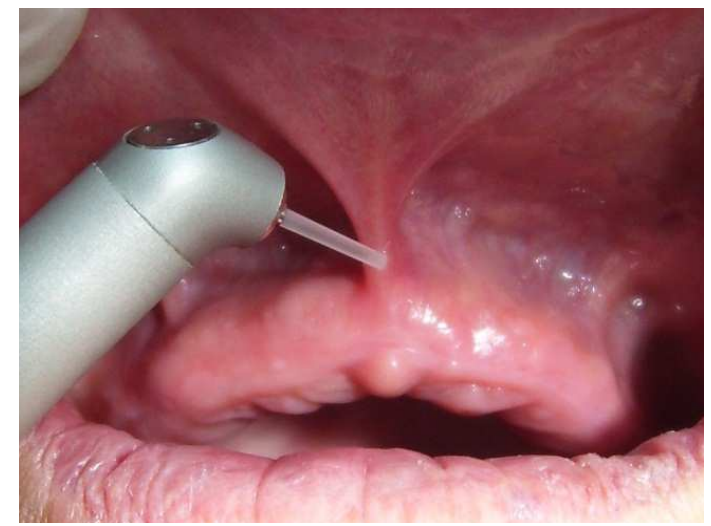

Figure 3. Laser procedure: After infiltration with anesthetic solution, the Er:YAG laser (LiteTouch, Syneron, Israel) was used with 1300-micron sapphire tip, in contact mode and power $200 \mathrm{~mJ}, 35 \mathrm{~Hz}$.

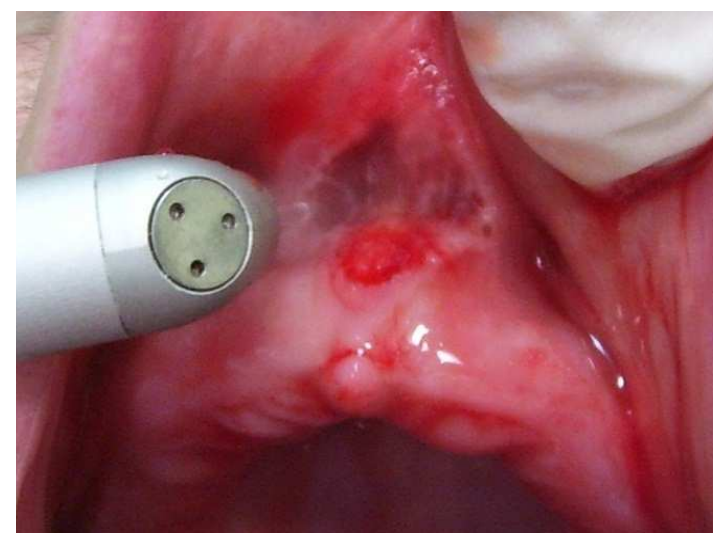

Figure 4. The contact sapphire tip and heavy water spray gently ablate the frenal attachment and underlying tissue down to the level of the periosteum. 


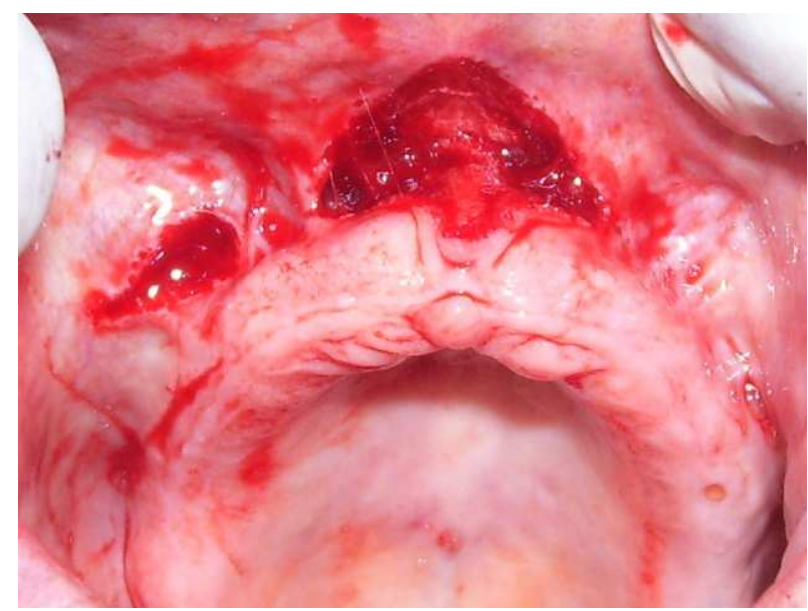

Figure 5. Immediately after the procedure. There is no charring, no burned tissue, and no profuse bleeding in the site. The laser produces a wet incision (some bleeding) as opposed to the dry incision that is produced by the $\mathrm{CO}_{2}$ laser.

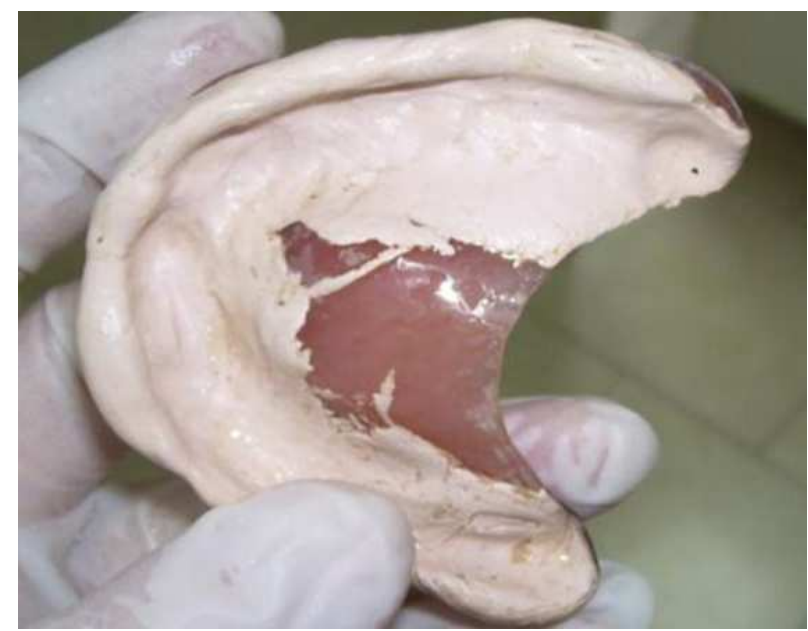

Figure 6. The preexisting upper denture was relined with a periodontal

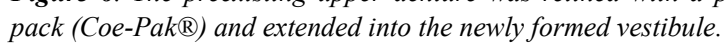

\section{Results}

Postoperative healing was uneventful and no wound infection could be found (Fig. 7a). In the paranasal test after three weeks we found vestibular depth of $1.71 \mathrm{~cm}$ (Fig. $7 \mathrm{~b})$. The examination after 6 months showed $1.16 \mathrm{~cm}$. In the distal measurement region from the beginning the reading was lower. After 7 days we measured a vestibular depth of $1.14 \mathrm{~cm}$, after 6 months we found a vestibular depth of $0.86 \mathrm{~cm}$. The patient assessed his individual pain level as moderate and light analgesic (Analgin, Sopharma, Bulgaria) was prescribed after surgery for two days. Operation time was 8.5 minutes including anesthesia performing. Seven days post operatively the old denture was relined with conventional denture acrylic. New denture was inserted one month and a half after the operative procedure (Fig. 8 and 9).

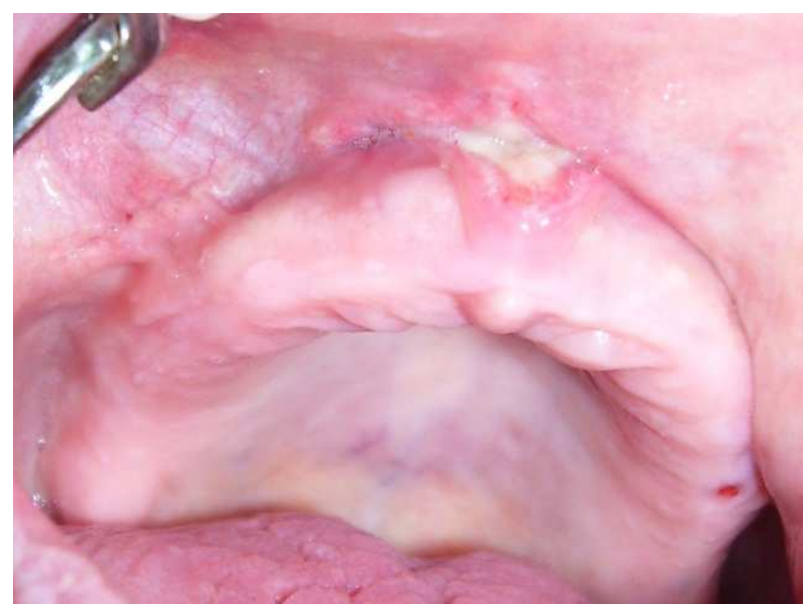

(a)

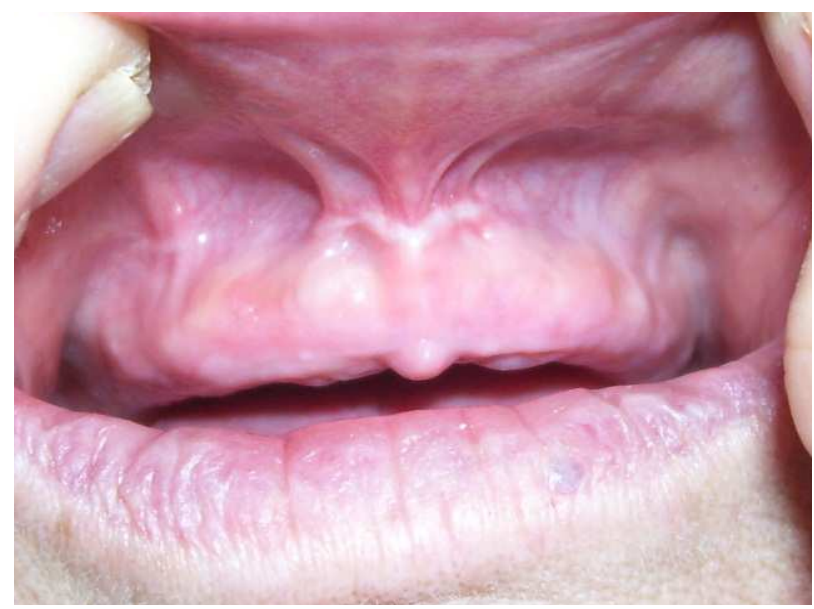

(b)

Figure 7. Healing process at seven days (a) at three weeks after surgery (b).

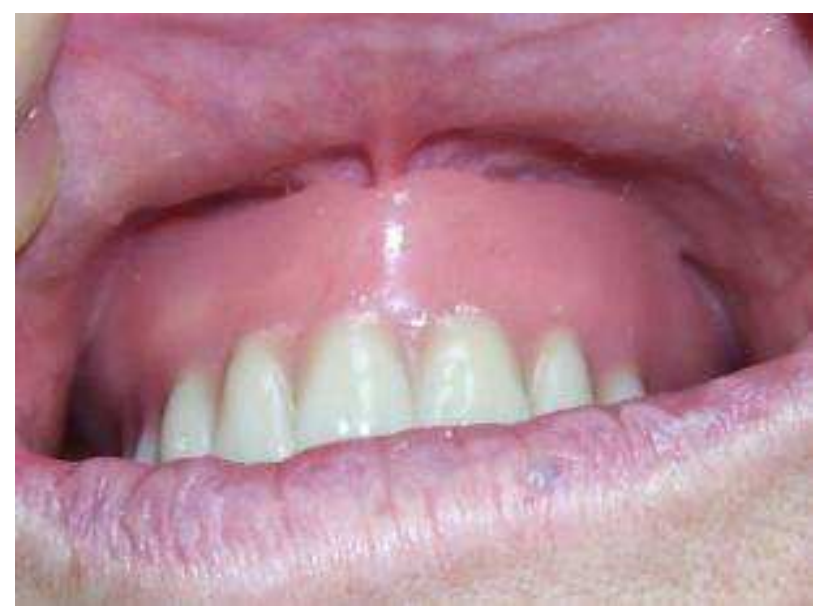

Figure 8. The new denture was inserted one month and a half after the operative procedure. 


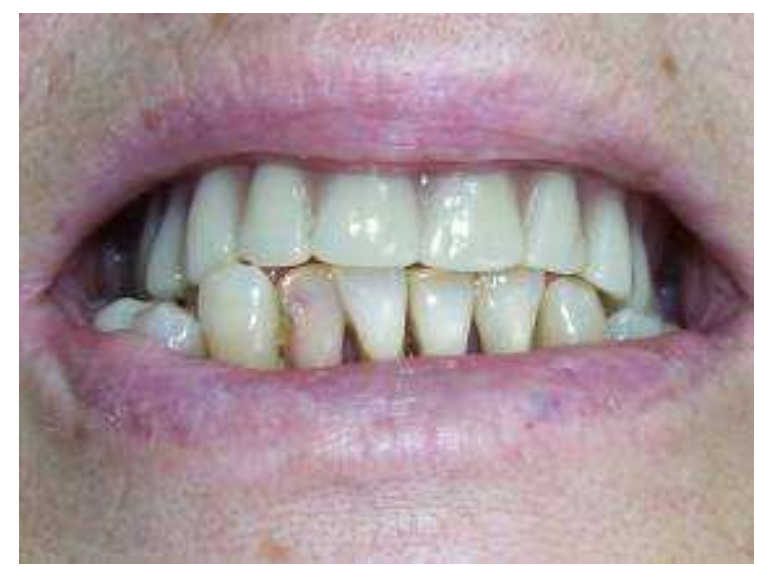

Figure 9. Stable function of the new denture during mastication.

\section{Discussion}

The Er:YAG laser emits wave length at $2.940 \mathrm{~nm}$ in the mid-infrared electromagnetic spectrum. Water is the dominant target chromophore for Er:YAG laser energy which currently has the highest absorption peak in water among any commercially available, FDA-approved dental lasers. These unique characteristics of the Er:YAG laser allow performing of very narrow layers of thermal mechanical tissue ablation with minimal collateral thermal consequences [8].

In the presented case report we used an Er:YAG laser (LiteTouch, Syneron, Israel) to deep the oral vestibulum of upper jaw in edentulous patient. When performing this procedure, there are two basic concepts under consideration-thermal expansion and heat transfer through conduction. The photobiology of this wavelength $(2.940$ $\mathrm{nm}$ ) is unique and has distinct benefits for the practitioners. If water is the dominant chromophore, the mechanical integrity of the extracellular matrix (more specifically the collagen) is not targeted directly. To achieve tissue removal, the heated water (intracellular steam) must expand first straining and then fracturing the extracellular matrix components (collagen). Because Er:YAG energy has such a high absorption peak in water, the thermal damage to the tissue is kept to a bare minimum as the thermal mechanical ablation takes place. The healing capacity of the laserirradiated tissue when looked at with this point is profound. Tomov et al., in a histomorphological study, reported for less thermally induced damage with Er:YAG laser in comparison with the diode laser [8] and this is supported by other authors [3, 5].

In using the Er:YAG laser we experienced a less time consuming preparation of the vestibular soft tissue. Bleeding on the other hand was minimal so we always had optimal overview of the operation site. Fixing the tissue in the fornix was very easy. The low pain after Er:YAG laser surgery is a phenomena described by many authors $[3,5,7$, 10]. The rational in this finding is the fact that during the operative procedure small nerve endings are welded and less susceptible for all kinds of irritations.

\section{Conclusion}

As laser use in the practice of general dentistry continues to increase, there will be many procedures that were once done by traditional mechanical methods, but will now be seen through laser safety glasses. If clinicians decide to use a laser for a dental procedure, they need to fully understand the character of the wavelength being used and the thermal implications and limitations of the laser energy. The above surgical case present the soft tissues options of Er:YAG wavelengths to create an easier procedure that a general dentist could certainly accomplish. This minimally invasive laser-assisted partial vestibuloplasty was accomplished with minimal anesthesia, minimal discomfort, no sutures, no antibiotics, and great patient satisfaction. Therefore, were indicated, we recommend the laser assisted operation technique for the partial vestibuloplasty to assure the patients a better postoperative outcome.

\section{References}

[1] Waite D.E, Overview and historical perspective of oral reconstructive surgery. Oral Surg, Oral Med, Oral Path1989: 68(4):495-498.

[2] Akin H, Tugut F, Guney U, Akar T. Shear Bond Strength of Denture Teeth to Two Chemically Different Denture Base Resins after Various Surface Treatments. J Prosthodont. 2013 Jul 25. doi: 10.1111/jopr.12081.

[3] Kesler G. Clinical applications of lasers during removable prosthetic reconstruction. Dent Clin North Am 2004;48:963969.

[4] Mahler P, Pouyssegur V, Rocca JP, De Moor R, Nammour S. Preprosthetic surgery of the edentulous maxilla: vestibular deepening with the aid of the $\mathrm{CO} 2$ laser. Rev Belge Med Dent 2009;64:108-113.

[5] Neckel C P, Vestibuloplasty: a retrospective study on conventional and laser operation techniques, Lasers in Dentistry 1999;76(5):18-23.

[6] Pogrel MA. The carbon dioxide laser in soft tissue preprosthetic surgery. J Prosthet Dent 1989;61:203-208.

[7] Tomov G. Laser surgery in everyday practice with Er:YAG laser LiteTouch. Dental Tribune (Bulgarian edition), 2011, 2:6-9.

[8] Tomov G, Bachurska S, Tashkova D, Ivanov G. Pathomorphological distinction between Er:YAG and diode lasers on the excisional biopsy of the oral mucosa. Russian Open Medical Journal, 2013 (2)1:44-49.

[9] Pick RM, Colvard MD Current Status of Lasers in Soft Tissue Dental Surgery, J Periodont 1993; 64(7):589-602.

[10] Pié-Sánchez J, España-Tost AJ, Arnabat-Domínguez J, GayEscoda C. Comparative study of upper lip frenectomy with the CO2 laser versus the Er, Cr:YSGG laser. Med Oral Patol Oral Cir Bucal. 2012 Mar 1;17(2):e228-32. 